Historic, Archive Document

Do not assume content reflects current scientific knowledge, policies, or practices. 



\section{The Roosevelt Strawberry}

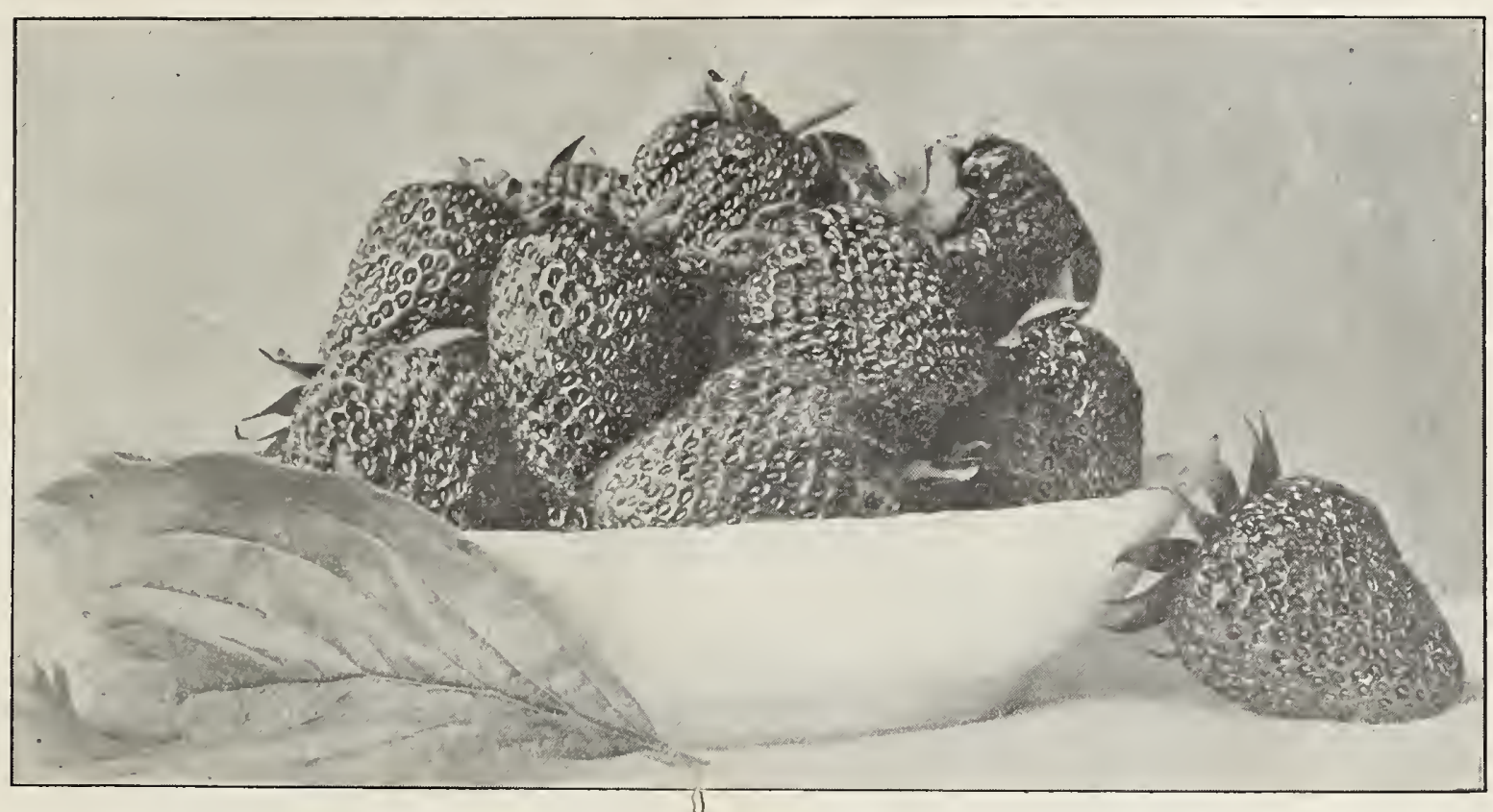

And why the name, ROOSEVELT? Because, he who made that name worthy is admitted by all, friend or foe, to be honest, vigorous and true. And that is what I ctaim for the ROOSEVELT STRA WBERRY.

'T is Honest in its every part, Vigorous in its growth and yield, and True in its form, color, taste, and canning qualities Hence the name, ROOSEVELT?

This cut shows the natural growth of the

\section{Roosevelt Strawberry}

'Tis an average cluster on which there are twenty-two perfect strawberries in the various degrees of development, by noting which you will understand my statement, that the picking season extends from two to three weeks (See next cutt)

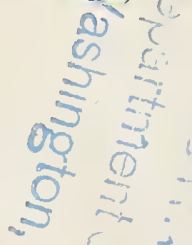

\section{T. B. WEST}

MAPLE BEND
NURSERY

$$
\text { PERRY, OHIO }
$$




\section{The Roosevelt Strawberry}

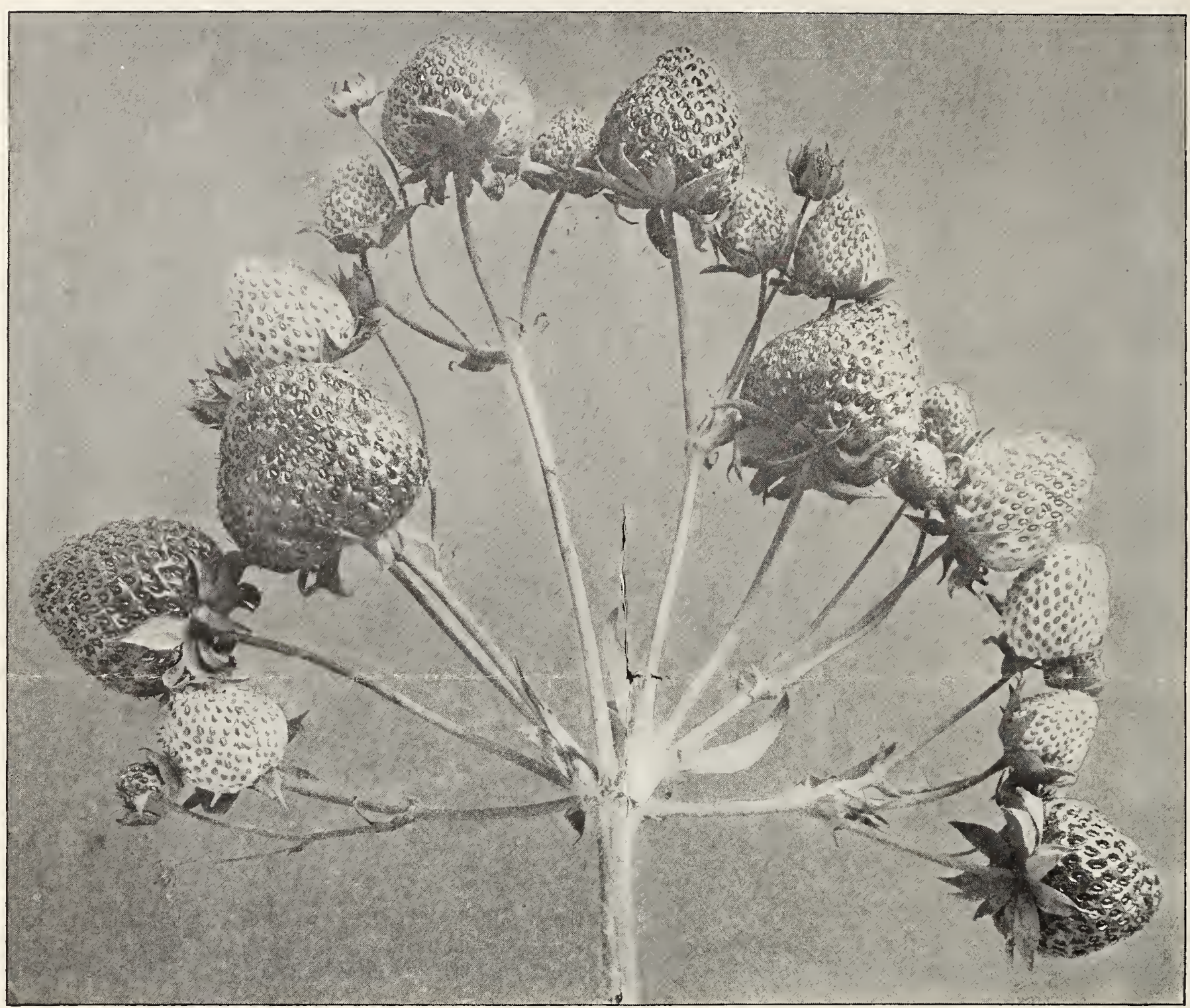

HERE we have the same bunch as shown in the preceding cut. You can count the berries yourself and you will find twenty-two perfect ones.

Note the sturdy growth. The stem is from six to eight inches long and very strong, so as to support the fruit from the ground.

If you will visit our fields in the fruiting season, you can see for yourself, or I will mail you samples upon receipt of ten cents in stamps to cover postage. 


\section{The Roosevelt Strawberry}

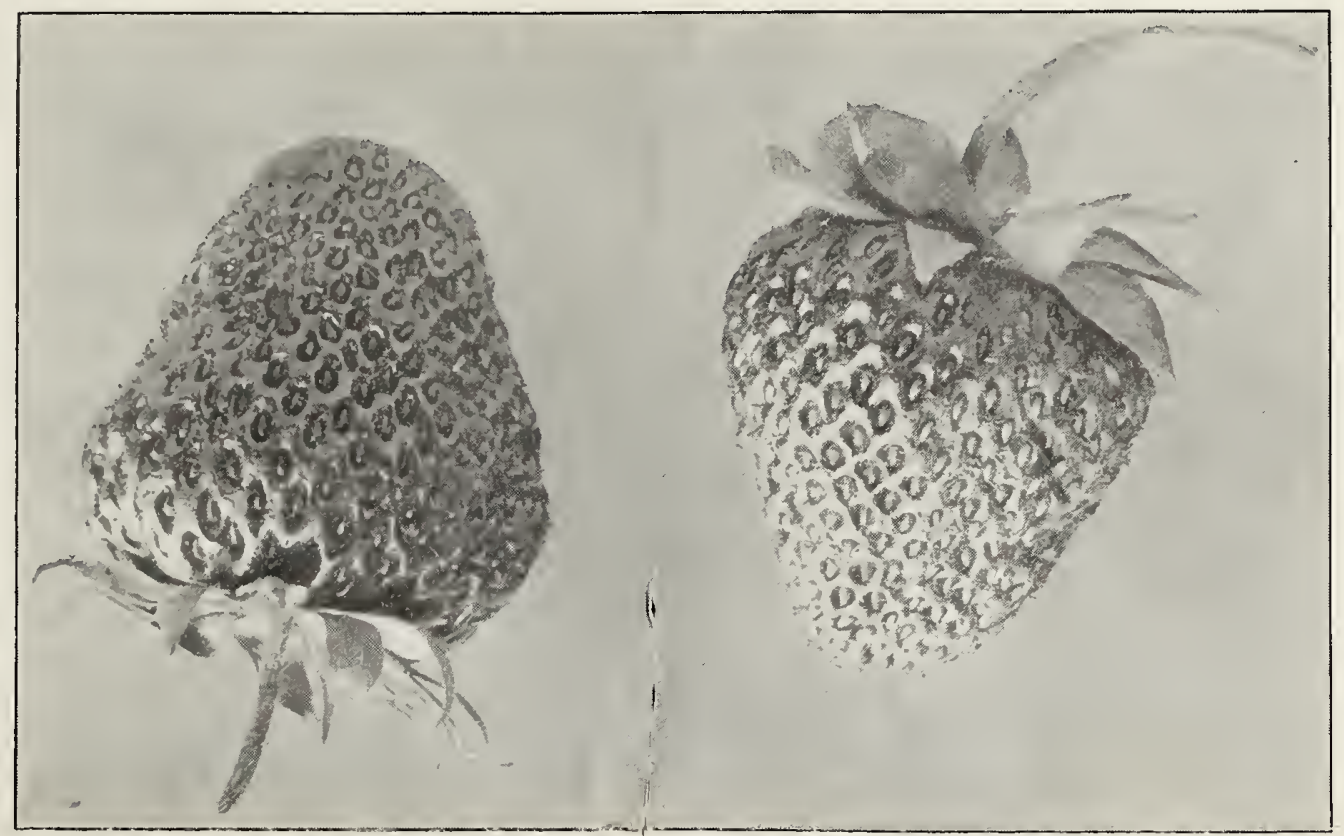

THIS cut gives you the natural size of the ROOSEVELT. 'Tis exact size of the 1 two berries photographed, and an average of the best developed berries grown in a three acre patch, on gravelly soil and without any special care or forcing in any way, and in the very dry season of 1909 .

Come and see for yourself in 1910 or send ten cents for postage for sample. 


\section{The Roosevelt Strawberry}

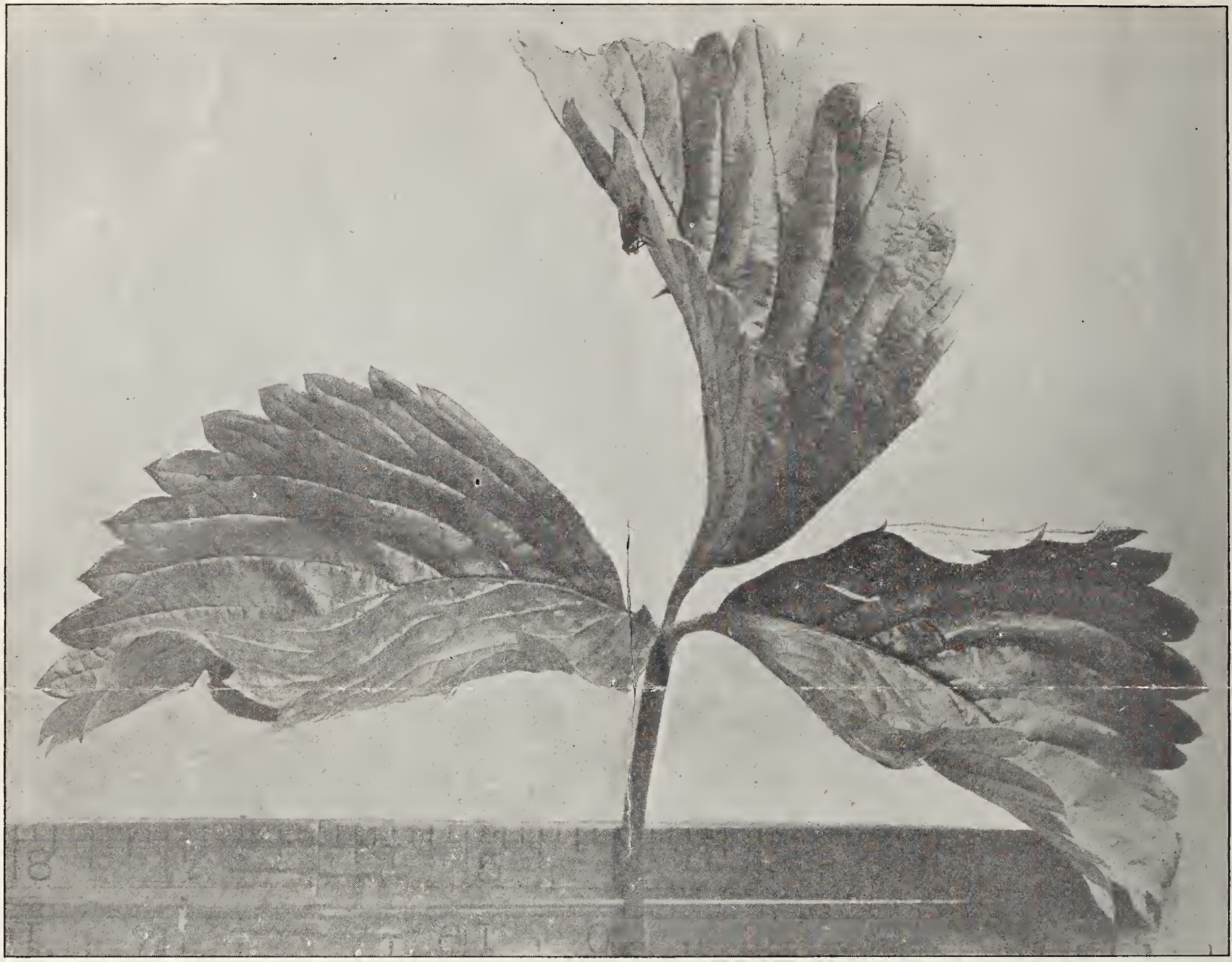

HERE you see the vigorous growth of the plant. Notice the size, eight inches from tip to tip.

(No strawberry race suicide here.) The foilage is lusty, the root large and long. The fruit abundant, beautifully shaped, a dark rich red inside and out; flavor unsurpassed, if equaled. Firm and solid, and like the namesake, will stand lots of rough handling and still be a perfect specimen of its kind.

If interested, send for prices.

T. B. WEST, MAPLEEND PERRY, OHIO 